\title{
As pílulas do Messias: salvação, negação e política de morte em tempos de pandemia
}

| ${ }^{1}$ Roberta D. F. C. Silva, ${ }^{2}$ Leandro A. P. Gonçalves |

\begin{abstract}
${ }^{1}$ Faculdade de Farmácia, Universidade Federal do Rio de Janeiro - Campus Macaé. Macaé-RJ, Brasil (robertadfcosta@gmail.com). ORCID: 0000-0003-2416-0810

2 Instituto de Saúde Coletiva, Universidade Federal Fluminense. Rio de Janeiro-RJ, Brasil (goncalves.lap@gmail). ORCID: 0000-0002-6795-8374

No ano de 2015, as panelas batiam como hoje. O registro do primeiro "panelaço" dirigido ao governo de Dilma Rousseff foi feito no dia 8 de março de 2015, em uma homenagem de tonalidade perversa ao Dia Internacional da Mulher (MAGALHÃES, 2020). Um ato que apresenta os valores de um processo social e político que traria nos anos seguintes consequências trágicas para todas e todos nós.

Como as panelas, foi da "cozinha industrial" de uma casa em Pomerode-SC, em junho de 2015, que outro acontecimento chamou a atenção da opinião pública. Carlos Kennedy Witthoeft era preso pela polícia militar catarinense por produzir e distribuir fosfoetanolamina (FOS), uma substância de suposto valor no tratamento do câncer, às pessoas que sofriam da doença (G1 SC, 2015). Ele montara uma unidade de produçáo fabril nos fundos da sua casa, onde produzia a FOS na forma de pílulas. Sua companheira, Aridina Witthoeft, acolhia as demandas e fazia a distribuição da fosfoetanolamina a quem desejasse usar, gratuitamente (PIOVEZAN, 2015).

Após 17 dias, Carlos saiu da prisão, nada arrependido. Contou que decidira produzir a FOS em casa após sua mãe, já idosa e muito debilitada, se recuperar de um câncer usando-a, em 2007. Não havia alternativas terapêuticas para o caso da sua mãe, dada a gravidade do quadro de saúde, e os médicos apontaram apenas possibilidades paliativas. Inconformado, Carlos soube da FOS e suas supostas 
propriedades milagrosas. Conseguiu o contato de um professor da Universidade de São Paulo, Gilberto Chierice, que produzia e distribuía a substância. Contou o caso da mãe ao professor; este lhe enviou o produto e as instruçôes posológicas para que a mãe de Carlos o tomasse (PIOVEZAN, 2015).

Seguindo as instruções e tratando a sua mãe, esta "curou-se" em 18 dias. A cidade toda soube do acontecimento, e Carlos passou a ter uma ideia fixa: oferecer aquele milagre a quem precisasse. Trocou mensagens com Gilberto Chierice, queria que o professor o ensinasse a produzir a FOS. Receoso a princípio, o químico não aceitou. Carlos foi incisivo, argumentou sobre o potencial da substância, de quantas vidas poderiam ser salvas. Gilberto cedeu, e o catarinense passou a ir constantemente a São Carlos, onde o professor o formou como "químico prático" em 4 meses. Formado, montou sua "cozinha industrial" em Pomerode no início de 2008; desde então, até junho de 2015, produziu a FOS e a distribuiu (PIOVEZAN, 2015).

Um pouco antes da prisão de Carlos, em 2014, uma portaria da USP proibira Gilberto Chierice de distribuir a FOS (INSTITUTO DE QUÍMICA DE SÃO CARLOS, 2014). Isto provocou, no estado de São Paulo, uma corrida das pessoas que faziam uso da substância ao Judiciário e ao Ministério Público para garantir o acesso à formulação. Esta dinâmica recursiva culminou, em outubro 2015, com a liminar concedida pelo ministro Edson Fachin, do Supremo Tribunal Federal, suspendendo decisão do Tribunal de Justiça de São Paulo que proibia a distribuição da FOS pela USP de São Carlos. Na interpretação do ministro, não havendo outras possibilidades terapêuticas para um determinado caso, a FOS servia como um fator atenuante para as dores, não se caracterizando como um medicamento (PENALVA, 2015).

Afinal, a FOS é um medicamento? Náo, nunca foi. Sempre foi utilizada como adjuvante na produção de medicamentos, nunca como princípio ativo. Não há e não havia, em 2015, qualquer evidência científica do benefício do seu uso em casos de câncer, nem estudos sobre a segurança da sua utilização na suposta dosagem que estava sendo recomendada e distribuída por químicos docentes e químicos práticos (PAUMGARTTEN, 2016). Para piorar, uma condição que esses "profissionais" colocavam era a necessidade de suspender todos os outros tratamentos em curso (G1 SÃO CARLOS E ARARAQUARA, 2015).

No mesmo mês da liminar de Edson Fachin, uma audiência pública no Senado trazia para a casa legislativa duas posiçóes sobre a FOS, já chamada por alguns de "a pílula do câncer”. Por um lado, médicos que prescreviam, químicos que produziam, 
pesquisadores que a estudavam e pessoas com câncer, prometiam e testemunhavam a cura do câncer através daquela pílula divina; por outro, representantes das instituiçóes da Saúde apresentavam a falta de evidências para a autorização da distribuição e do uso da FOS para os casos de câncer (TV SENADO, 2015).

Entre outubro de 2015 e abril de 2016, quando a distribuição e o uso da fosfoetanolamina foi autorizada na forma da Lei n. 13.269 (2016) pela presidenta Dilma Rousseff, um processo político intenso se instaurou nas casas legislativas em torno do tema. Além disso, grupos de pesquisadores se formaram e estudaram o uso e a forma de produção da FOS como era feita por Gilberto Chierice, atestando tanto a falta de evidências do efeito terapêutico sobre o câncer daquela formulação, quanto à falta de qualidade farmacêutica da produção do químico da USP. Ainda assim, a presidenta autorizava seu uso e distribuição (PAUMGARTTEN, 2016). Que forças incidiam nessa decisáo?

O processo político da autorização do uso e da distribuição da FOS ocorreu paralelamente ao processo político de impeachment de Dilma Rousseff. Ela foi deposta poucos dias depois de assinar a lei. Câncer e corrupção eram os temas que tomavam a opinião pública e as casas legislativas. Para os dois temas, duas soluçôes fáceis: uma pílula e a deposição de uma presidenta. Para essa solução, os dois processos compartilharam a força das bancadas da bala, do boi e da bíblia ${ }^{1}$ (CÂMARA DOS DEPUTADOS, 2015; MEDEIROS; FONSECA, 2016) e colocaram em evidência uma figura pública em comum: Jair Bolsonaro.

Jair Bolsonaro, além de ter seu nome entre os que escreveram a lei aprovada na Ccâmara dos Deputados e depois sancionada por Dilma (GARCIA, 2016), atuou como representante da FOS, produzindo vídeos e disseminando-os em suas redes sociais. Neles, Bolsonaro referia o caráter salvador da molécula, colocando-se como alguém que estaria atuando para garantir que todo brasileiro pudesse ter acesso a ela (BOLSONARO, 2016). Usando táticas e estratégias de propaganda e atuação política que vimos serem intensificadas nos anos seguintes, gostaríamos de destacar um traço de suas peças audiovisuais: apresentar-se como o "Messias", alguém capaz de oferecer a salvação às pessoas.

Em 2020, Jair Messias Bolsonaro é o presidente da República brasileira. República recentemente atingida pela epidemia de um vírus ainda pouco conhecido, o coronavírus, ou, mais precisamente, o SARS CoV-2. Contra a doença que este vírus provoca em humanos, a Covid-19, não se tem uma terapêutica conhecida. Apoiando- 
se em evidências de pesquisas antigas, feitas in vitro, o presidente da República anuncia que a cloroquina (CQ) é a solução contra o vírus e que o Brasil a testará e a produzirá em massa (FONSECA, 2020). Na falta de testes diagnósticos e capacidade de produzir equipamentos de proteção individual (EPI), uma promessa milagrosa.

Contudo, a problemática aqui é outra em relação a FOS: a CQ é um medicamento que tem o uso clínico e suas formas de produção bastante conhecidas. Ao colocar a promessa à nação, o presidente não considerou que o motivo pelo qual o Brasil não é capaz de produzir testes diagnósticos e EPIs em massa é o mesmo que torna frágil a promessa medicamentosa. O Brasil é inteiramente dependente de outras naçóes para a aquisição de qualquer tecnologia sanitária. A dependência do país nos permite apenas adquirir (importar), pois não somos capazes de produzir qualquer solução sanitária para a crise provocada pelo SARS-CoV-2.

Como a FOS e a CQ são os nossos apoios argumentativos, focalizaremos a nossa análise posterior no setor industrial farmacêutico, evidenciando que a condição vulnerável do Brasil não é um mero desleixo. É uma política de vulnerabilização e produção de morte que se dirige a determinados grupos populacionais.

\section{Dependência em tempos de necropoder}

As soluçôes messiânicas de Jair Bolsonaro são o combustível da sua base social, contudo o SARS-CoV-2 avança rápido, exigindo respostas sanitárias concretas e urgentes. A epidemia pelo vírus chegou não só levando vidas por onde passa; ela expóe também os modos de atuação dos Estados nacionais, as fragilidades dos governos, dos governantes, da sociedade. Especialmente em nosso país, o vírus que asfixia, dá fôlego às nossas chagas: evidencia as fragilidades estruturais do nosso sistema de saúde e apresenta de forma aguda nossa vulnerabilidade ao sermos convocados a uma corrida mundial por evidências e insumos.

Quanto à CQ e seu metabólito, a hidroxicloroquina (HCQ), estas ganharam visibilidade no tratamento da Covid-19 a partir de estudo realizado na França, que atestou resultados promissores para o uso da HCQ em associação com a azitromicina (COLSON et al., 2020). Entretanto, a comunidade científica internacional recebeu o estudo com precaução, visto que este não apresentou um grupo controle na metodologia empregada. A ausência de controle - pacientes que não fizeram uso das substâncias - não permite a associação direta do uso da HCQ na melhora ou não 
dos pacientes. O British Medical Journal (BMJ), em um dos seus editoriais, alertou sobre o uso prematuro das substâncias no tratamento da Covid-19 e pediu cautela no uso da CQ e da HCQ, chamando a atenção para os efeitos adversos que provocam (FERNER; ARONSON, 2020). Ao mesmo tempo, se intensificaram ao redor do mundo estudos de outros medicamentos de classes diferentes: antirretrovirais, biofármacos, entre outros.

No entanto, dois chefes de Estado se mostraram empolgados com a HCQ e CQ para o tratamento da Covid-19: Donald Trump e Jair Bolsonaro. O brasileiro, que em seus constantes pronunciamentos durante o mês de março dizia que as consequências pela infecção por SARS-CoV-2 eram semelhantes a uma "gripezinha", apresentou um discurso ambíguo: ao mesmo tempo que minimizava a doença, revelava sua cura através do uso da CQ. Sem qualquer prudência, tornou a importação do princípio ativo, distribuição em território nacional pelo Laboratório Químico e Farmacêutico do Exército e o uso do medicamento como estratégia central para o enfrentamento à epidemia (FONSECA, 2020).

De traço ousado, o presidente atropelou alguns limites profissionais, e o decoro do cargo, ao prescrever a forma de uso da CQ à nação. Contrariando as diretrizes do Ministério da Saúde (MS), que apontam a utilização da CQ para formas graves e críticas da doença (BRASIL, 2020), Bolsonaro sugeriu às pessoas, publicamente, o tratamento com o medicamento já nos primeiros sintomas aparentes de adoecimento (HENRIQUE, 2020). Nas redes sociais, local onde opera a base política e tecnológica do presidente, que se caracteriza por serem robôs em grande parte (KALIL; SANTINI, 2020), cresceu o número de pequenos textos exaltando o uso da CQ, ao mesmo tempo que surgiam memes atacando oponentes políticos que optaram pela estratégia de distanciamento amplo.

Diante da impossibilidade nacional de apresentarmos soluçôes sanitárias que pudessem ser agregadas ao distanciamento amplo, atenuando-o, a CQ torna-se a "bala mágica" que dá conta dos problemas dos brasileiros. Em especial, para uma parcela dos brasileiros: aqueles que hoje fazem carreata pelo fim do distanciamento amplo, pela reabertura do comércio e consequente retomada econômica. Se a FOS foi a cura do câncer, a CQ é agora a cura do coronavírus e da economia brasileira. Não haveria a necessidade do distanciamento, temos a cura!

A posição do presidente, que contraria as diretrizes de distanciamento amplo do próprio MS, poderá fazer do Brasil um dos países com maior número de vítimas 
pela Covid-19, dadas as projeçôes recentemente atualizadas pelo Imperial College, de Londres (VERITY et al., 2020). É possível que Bolsonaro pense na tradicional chave utilitária de sua ideologia liberal: a morte de idosos, pessoas com a saúde fragilizada e populaçôes vulnerabilizadas não é uma boa saída sanitária para a crise econômica e estrutural brasileira?

Outro aspecto que nos parece importante nessa estratégia é que o foco na CQ esconde a nossa insuficiência referente aos testes diagnósticos. Testamos pouco, o que limita a percepção da extensão da epidemia no território nacional. E isso ocorre pela falta de capacidade de produção de reagentes, já que o Brasil optou por um modelo político e econômico, no início dos anos 90, de desmonte da indústria de produtos químicos e farmoquímicos, levando à intensificação da dependência internacional nesses setores. Em um estudo realizado por Rodrigues et al. (2018), foi possível observar a escolha do Brasil, desde os anos 90, por apostar na produção e exportação de commodities e importar insumos químicos, farmacêuticos e farmoquímicos, o que tornou o país altamente dependente do mercado internacional. Dependência essa que atrapalha, inclusive, a capacidade do país de produzir a CQ, já que o insumo farmacêutico ativo é importado da Índia. Essas escolhas políticas incidem hoje sobre nós, em um momento no qual as diversas naçóes do mundo buscam os mesmos insumos, princípios ativos e equipamentos.

Em ensaio recente, Achille Mbembe aponta que um "mero remendo não será suficiente para dar conta das mudanças que estão em curso em um mundo asfixiado pelo coronavírus" (MBEMBE, 2020). Este pensador também nos apresenta a noção de necropoder, que caracteriza o agir organizado sobre determinadas populaçóes estabelecendo sobre elas uma política de morte, a necropolítica (MBEMBE, 2018).

Articulamos, neste ensaio, a operação do necropoder com a dinâmica do Sistema Interestatal Capitalista - SIC (FIORI, 2014): pensando nosso lugar na geopolítica internacional, onde estaríamos? Certamente, em área de penumbra, entre os territórios "condenados da terra", que servem à infinita extração produtiva. O silêncio ensurdecedor da situação da epidemia pelo SARS-CoV-2 no continente africano e a ambiguidade da condução do enfrentamento à epidemia no Brasil talvez sejam importantes indícios dos lugares que ocupam tais territórios na geopolítica mundial. A geopolítica do SIC opera o necropoder e agrava nossa situação de subordinados no mercado internacional. Quem terá a preferência na compra de insumos e equipamentos para conter a pandemia enquanto milhares de ingleses e americanos 
morrem diariamente? Práticas de confisco de materiais sanitários têm sido operadas pelos Estados Unidos sem qualquer constrangimento, extraviando-os de países que já tinham pago por eles, atualizando a pirataria neste nosso tempo (BBC, 2020).

Internamente, o necropoder se capilariza no território nacional, marcando nossa colonialidade. Seus operadores estão na presidência da república e estão nas ruas, de máscaras, em seus SUVs e sedans de luxo, agora, na segunda semana do mês de abril, próximo ao colapso do sistema de saúde brasileiro, exigindo a reabertura do comércio e que os trabalhadores voltem a seus postos. A preocupação deles é a quebra da economia, algo que vale muito mais que as vidas tão pouco valiosas daqueles que estão mais suscetíveis ao vírus.

Diante disso, do estrago feito pelo presidente e sua base de apoio, nos somamos entre os que esperam uma poderosa "bala mágica" que nos salve. Alertamos, apenas, que se ela aparecer, precisaremos fazer como Carlos Witthoeft: na falta de um parque industrial capaz de nos abastecer, precisaremos de soluçôes igualmente mágicas. Quem sabe montar uma cozinha industrial nos fundos de nossas casas?

\section{Referências}

BBC. Coronavírus: EUA são acusados de "pirataria" e "desvio" de equipamentos que iriam para Alemanha, França e Brasil. Portal BBC, 2020. Disponível em: <https://www.bbc.com/ portuguese/internacional-52166245>. Acesso em: 19 abr. 2020.

BOLSONARO, C. Bolsonaro - luta contra o câncer. Portal Youtube, 2016. Disponível em: https://www.youtube.com/watch?v=zeBL2n9knCY . Acesso em: 18 abr. 2020.

BRASIL. Ministério da Saúde. Diretrizes para diagnóstico e tratamento da Covid-19. Brasília. 8 de Abril de 2020.

CÂMARA DOS DEPUTADOS. Grupo de trabalho e representaçáo - fosfoetanolamina. Portal Câmara dos deputados, 2015. Disponível em: <http://www2.camara.leg.br/atividade-legislativa/ comissoes/comissoes-permanentes/cssf/conheca-a-comissao/subcomissoes/grupo-de-trabalhofosfoetanolamina/grupo-de-trabalho-fosfoetanolamina>. Acesso em: 18 abr. 2020.

COLSON, P. et al. Chloroquine and hydroxychloroquine as available weapons to fight COVID-19. Int J Antimicrob Agents, 2020. Disponível em: <https://www.ncbi.nlm.nih.gov/ pubmed/32145363>. Acesso em: 18 abr. 2020.

FERNER, R.; ARONSON, J. Chloroquine and hydroxychloroquine in covid-19: Use of these drugs is premature and potentially harmful. BMJ 2020. Disponível em: <https://www.bmj. com/content/bmj/369/bmj.m1432.full.pdf $>$. Acesso em: 18 abr. 2020. 
FIORI, J. L. História, estratégia e desenvolvimento: para uma geopolítica do capitalismo. São Paulo: Boitempo, 2014.

FONSECA, P. Bolsonaro anuncia aumento de produção de cloroquina; uso contra coronavírus não é comprovado. Portal UOL, 2020. Disponível em: <https:/economia.uol.com.br/noticias/ reuters/2020/03/21/bolsonaro-anuncia-aumento-de-producao-de-cloroquina-uso-contracoronavirus-nao-e-comprovado.htm>. Acesso em: 18 abr. 2020.

GARCIA, M. GT da Fosfoetanolamina tem dia com eventos para viabilizar a liberação da substância. Portal Câmara dos Deputados, 2016. Disponível em: <https://www2.camara.leg.br/ atividade-legislativa/comissoes/comissoes-permanentes/cssf/conheca-a-comissao/subcomissoes/ subcomissoes-2017/subfarma-2017/grupo-de-trabalho-fosfoetanolamina/noticias/noticias/gtda-fosfoetanolamina-tem-dia-com-eventos-para-viabilizar-a-liberacao-da-substancia>. Acesso em: 18 abr. 2020.

G1 SÃO CARLOS E ARARAQUARA. Pesquisador acredita que substância desenvolvida na USP cura o câncer. Portal G1, 2015. Disponível em: <http://g1.globo.com/sp/sao-carlos-regiao/ noticia/2015/08/pesquisador-acredita-que-substancia-desenvolvida-na-usp-cura-o-cancer. html>. Acesso em: 18 abr. 2020.

G1 SC. PM prende homem suspeito de fazer medicamentos irregulares em SC. Portal G1, 2015. Disponível em: <http:/g1.globo.com/sc/santa-catarina/noticia/2015/06/pm-prende-homemsuspeito-de-fazer-medicamentos-em-laboratorio-irregular.html>. Acesso em: 19 abr. 2020.

HENRIQUE, G. A exaltação da cloroquina por Bolsonaro na TV. PortalNEXO, 2020. Disponível em: <https://www.nexojornal.com.br/expresso/2020/04/08/A-exalta\%C3\%A7\%C3\%A3o-dacloroquina-por-Bolsonaro-na-TV>. Acesso em: 20 abr. 2020.

INSTITUTO DE QUÍMICA DE SÃO CARLOS. Esclarecimentos à Sociedade. Portal USP, 2014. Disponível em: <http://www5.iqsc.usp.br/quarentena/esclarecimentos-a-sociedade/>. Acesso em 19 abr. 2020.

KALIL, I.; SANTINI, R. M. "Coronavírus, Pandemia, Infodemia e Política”. Relatório de pesquisa. Divulgado em 01 de abril de 2020. 21p. São Paulo / Rio de Janeiro: FESPSP / UFRJ. Disponível em: <https://www.fespsp.org.br/store/file_source/FESPSP/Documentos/ Coronavirus-einfodemia.pdf> Acesso em: 20 abr. 2020.

MAGALHÃES, G. Símbolo latino-americano, panelaço marcou Dilma e foi usado de esquerda à direita. Portal FOLHA, 2020. Disponível em: <https://www1.folha.uol.com.br/poder/2020/03/ simbolo-latino-americano-panelaco-marcou-dilma-e-foi-usado-de-esquerda-a-direita.shtml>. Acesso em: 19 abr. 2020.

MBEMBE, A. Necropolitica. 3. ed. São Paulo: n-1 edições, 2018. 80 p.

. O direito universal a respiração. Editora n-1. Disponível em: <https://n-1edicoes. org/020>. Acessado em: 11 abr. 2020. 
MEDEIROS, E.; FONSECA, B. As bancadas da Câmara. Portal Publica, 2016. Disponível em: <https://apublica.org/2016/02/truco-as-bancadas-da-camara/> . Acesso em: 23 abr. 2020.

PAUMGARTTEN, F.J.R. Sobre a alegada eficácia anticâncer da pílula de fosfoetanolamina, fragilidade da evidência científica e preocupaçóes éticas. Vigil. sanit. Debate, v. 4, n. 3, p. 4-12, 2016.

PENALVA, J. Fosfoetanolamina: a quintessência da judicialização. Portal JOTA, 2015. Disponível em: <https://www.jota.info/paywall?redirect_to=//www.jota.info/opiniao-e-analise/ artigos/fosfoetanolamina-a-quintessencia-da-judicializacao-21102015>. Acesso em: 19 abr. 2020. PIOVEZAN, S. "Consciência em paz”, afirma homem preso por doar cápsula contra câncer. Portal G1, 2015. Disponível em: <http://g1.globo.com/sp/sao-carlos-regiao/noticia/2015/08/ consciencia-em-paz-afirma-homem-preso-por-doar-capsula-contra-cancer.html>. Acesso em: 19 abr. 2020 .

RODRIGUES, P. H. A. et al, A evolução recente da indústria farmacêutica brasileira nos limites da subordinação econômica. Physis. Rio de Janeiro, v. 28, n. 1, 2018.

TATEMOTO, R. Bancada BBB se reconfigura e pode ampliar influência nos próximos quatro anos. Portal Brasil de Fato, 2019. Disponível em: <https://www.brasildefato.com.br/2019/02/12/ bancada-bbb-se-reconfigura-e-pode-ampliar-influencia-nos-proximos-quatro-anos $>$. Acesso em: 21 abr. 2020.

TV SENADO. Debate sobre a Fosfoetanolamina no Senado Federal - (completo) em 29/10/2015. Portal Youtube, 2015. Disponível em: <https://www.youtube.com/watch?v=jLX0_bT8Gh0>. Acesso em: 18 abr. 2020.

VERITY et al. Estimates of the severity of coronavirus disease 2019: a model-based analysis. Lancet Infectious Diseases, 2020. Disponível em: <https:/www.thelancet.com/journals/laninf/ article/PIIS1473-3099(20)30243-7/fulltext>. Acesso em: 18 abr. 2020.

\section{Nota}

${ }^{1}$ As bancadas do boi, da bíblia e da bala (ou BBB, como o famoso programa de televisão), são os apelidos das frentes parlamentares do agronegócio e dos evangélicos, além do núcleo ativo de deputados que defendem uma linha de enfrentamento violento na segurança pública e mais acesso da população às armas de fogo (MEDEIROS; FONSECA, 2016; TATEMOTO, 2019). 